\title{
RESCATE DE LA DEUDA BANCARIA EN MÉXICO*
}

\section{Ricardo Becerra***}

\section{INTRODUCCIÓN}

El desenvolvimiento del debate en torno al Fondo Bancario de Protección y Rescate al Ahorro (Fobaproa), que lleva meses y que ha involucrado a casi todos los actores políticos y sociales, ha encontrado como primer obstáculo la parcialidad de las discusiones. En México todos hablamos del Fobaproa, pero ante la acumulación caótica de opiniones divergentes, por su sentido y por su método, se tiene la impresión de una densa opacidad, que su complejidad esencial está reservada a muy pocos y por ello se escapa al entendimiento de los que no son especialistas!.

De ese ambiente se benefician dos posturas aparentemente contradictorias: por un lado la que medra de la confusión sin hacerse cargo de la complejidad real de los problemas, y por otro, la que prescinde de la discusión pública y cree que la razón de los problemas económicos está reservada a una élite ilustrada. Propensión demagógica y retraimiento tecnocrático colocan un velo al debate público y han hecho parecer imposible y vana la búsqueda de alguna solución.

Este artículo es un esfuerzo por entender; que si bien es necesario simplificar, se intenta no confundir la consigna con la explicación y no evadir lo esencial. A estas alturas, es difícil agregar novedades a la discusión así que nos proponemos una suerte de recapitulación: historia, problemas medulares, impugnaciones y propuestas de salida.

El Fobaproa es un problema de política económica de gran complejidad y de la mayor urgencia: de su solución depende que decenas de miles de personas honestas puedan pagar sus deudas pero también la viabilidad del sistema financiero mexicano, es decir, la viabilidad del corazón de la economía contemporánea

\section{LA HISTORIA}

Primero de mayo de 1990. Luego del tradicional desfile, ante varios dirigentes empresariales, se da la noticia: la Cámara de Diputados estaba por recibir una iniciativa para privatizar las instituciones bancarias. El hecho confirmaba la voluntad presidencial de reconciliar y de acercar a la comunidad empresarial con el gobierno.

"Que la IP sea cada vez más y que el Estado sea cada vez menos", la fórmula del importante empresario Juan
Sánchez Navarro, no podía encontrar una mejor forma para concretarse. Y el entonces presidente, Carlos Salinas, demostraba dos cosas: la decisión de llevar a cabo todas las rectificaciones necesarias al populismo estatal y de sellar a piedra y plomo cada uno de los componentes del modelo neoliberal, en este caso, el de la privatización.

En junio de 1991 -el régimen en su cenit- se realizó la primera subasta bancaria, que vendió al Multibanco Mercantil en un precio 1,6 veces mayor a su valor en libros. La historia se repetiría con todas las instituciones bancarias, los banqueros estuvieron dispuestos a pagar un precio altísimo al adquirir un banco; la pregunta es ¿por qué?

Por una parte, en ese momento existía una euforia en las expectativas del crecimiento económico: se suponía que estaban dadas las condiciones para una recuperación rápida de cuanto habían desembolsado. También porque el marco legal protegería a los bancos nacionales de la competencia: no se permitiría la llegada de bancos del exterior. Pero existe también una razón más negra: las condiciones de pago. Algunos nuevos banqueros no pusieron de su dinero, sino que solicitaron crédito ¿a quien? al banco que iban a comprar o algún otro recién privatizado. La venta no era pues con dinero constante y sonante, sino con pasivos. Y todavía más: algunas instituciones financieras gubernamentales dieron créditos "complementarios" a los nuevos accionistas: el Estado subido en un tío vivo el cual vende, presta y cobra sobre una misma operación.

Pero lo peor no estuvo allí: las nuevas instituciones estarían sujetas a una regulación y a una supervisión extraordinariamente débil y condescendiente. Durante casi diez años el gobierno fue al mismo tiempo dueño y cliente mayor de los préstamos. No es de sorprender que la supervisión fuera especialmente laxa. Luego de la privatización el esquema casi no fue modificado. Así, cuando la banca dejó de pertenecerle, el gobierno se quedó sin palancas suficientes para vigilar las operaciones de los bancos y de los nuevos

* Debo agradecer la lectura, la discusión y los comentarios críticos que Luis E. Giménez Cacho hizo al presente texto.

** Analista de temas políticos y económicos en México. Universidad Nacional Autónoma de México.

1. Justamente el mismo día que el PRD hacía su consulta nacional, Reforma publicaba una encuesta en la que el 60 por ciento de ciudadanos, reconocía no entender; y del 40 por ciento que dijo comprender, un alto porcentaje daba respuestas absolutamente contradictorias. 
banqueros. La Comisión Nacional Bancaria había mostrado su cabal ineficacia durante los diez años. No hubo un reciclamiento de los inspectores bancarios. Guillermo Prieto Fortún, un especialista en impuestos, quedó a cargo de una supervisión que debía ser radicalmente nueva, para instituciones mucho más complejas y flexibles, en un momento de globalización de las operaciones. Esta laxitud en la vigilancia no parece un descuido sino una decisión política, una compensación legal a cambio del alto costo que los nuevos banqueros estuvieron dispuestos a pagar.

Al terminar la privatización, el Presidente de la República y el Secretario de Hacienda presumieron haber vendido la banca en más del doble de lo esperado (14 mil millones de dólares) y que ese dinero amortizaría deudas, forjaría un fondo de contingencia y se canalizaría al gasto social.

Triunfo pírrico: ávidos por recuperar sus desembolsos, los banqueros dieron rienda suelta a sus instintos, abriendo todo tipo de programas de crédito en operaciones riesgosas. Por ejemplo, el crecimiento del crédito hipotecario entre 1992 y 1994, fue el más importante en la historia del país (equivalente al 2 por ciento del PIB). Y en su momento de gloria, el crédito creció cinco veces más que el PIB. Para diciembre de 1992 la cartera vencida (los préstamos difíciles de cobrar) representaba el 5.3 del total, para 1994, el 7.3; o sea que las deudas retrasadas crecieron $40 \%$ en $\tan$ solo dos años. Hacia finales de 1993 había bancos que arrastraban tres veces más la proporción que tenían cuando fueron privatizados.

Veamos el encadenamiento de los hechos: los bancos son vendidos a altísimos precios que serían, según Salinas, la prueba irrecusable del éxito de la privatización; a cambio se permitió que los bancos fueran comprados mediante operaciones cruzadas, con préstamos del propio gobierno y en ocasiones sin cuidar la cabal honestidad del comprador; también se decidió que la ley que los regularía fuera muy débil, y en esas condiciones, los banqueros dieron rienda suelta a un crecimiento del crédito altamente riesgoso y al final insostenible. Todo esto creó el problema. La única palanca que quedaba disponible si el problema estallaba era el Fobaproa.

\section{ANTES DEL SALVAMENTO}

En 1994, el problema fue este: los bancos otorgaron préstamos a largo plazo con recursos de capital a corto plazo que obtuvieron de los ahorradores. Los bancos por sí solos no podían conseguir suficientes recursos para pagar sus propias obligaciones. Prestaron mucho más de lo que era posible sostener.

En tales condiciones ¿no era mejor dejar que cerraran los bancos inviables? ¿por qué vino el rescate? Primero porque eran muchos bancos; segundo, porque sus inversionistas, sus ahorradores, que no tienen nada que ver con el manejo financiero, hubieran perdido sus recursos; pero también porque si un buen número de bancos quiebra, se desmoronaría el sistema de pagos. El 90 por ciento de los pagos de toda la economía, se hacen a través de los bancos: nóminas, deudas, transferencias, cambios de divisas, todas las empresas y todas las actividades económicas atraviesan o necesi- tan de un banco. En México los pagos suman diariamente decenas de miles de millones de pesos. Por eso, resultaría desquiciante la quiebra en serie de varios bancos.

Hasta antes de la gran crisis de 1929, cuando los bancos quebraban, los depositantes se quedaban sin sus ahorros: una destrucción completa de riqueza. Hoy, en la mayoría de países existen diferentes garantías gubernamentales para que eso no ocurra. El piso legal que apoyaría el ahorro en México proviene de la Ley de Instituciones de Crédito que crea a su vez en 1986 el Fondo de Apoyo Preventivo para las Instituciones de Banca Múltiple (Fonapre). Su misión era proteger "la estabilidad financiera de las instituciones de banca múltiple y evitar que los problemas que enfrenten resulten en prejuicio de los créditos a su cargo". Se trata del seguro de depósito, en su versión mexicana.

Mientras la banca estuvo en manos del Estado no había necesidad de hacer explícita la garantía, pero cuando las instituciones se privatizan, se convierte en una necesidad. Pensando en la banca privatizada, en 1990 se crea el protagonista de esta historia, el Fobaproa, cuyo fin es el de "realizar operaciones preventivas tendientes a evitar problemas financieros que pudieran presentar las instituciones de banca múltiple, así como procurar el cumplimiento de obligaciones a cargo de dichas instituciones" (Ley de Instituciones de Crédito). Se trata de un fondo de dinero-inicialmente aportado por los propios bancos- que estaba ahí para asistir ante cualquier contingencia.

Esa garantía de depósitos en los bancos, sin embargo, dio a sus flamantes propietarios otras peligrosas tentaciones: prestar dinero a deudores arriesgados, a una tasa de interés relativamente alta, aunque no sean capaces de devolver el dinero. Si resulta que pueden pagar, el banco habrá ganado en una operación con alto rendimiento. Si no puede pagar, el banco se retira y deja que el fondo financie la maniobra. Si sale águila gana el banco, si sale sol pagan los contribuyentes.

Insisto: el Fobaproa fue una bolsa de recursos que aportaron los propios banqueros. Pero las primeras contingencias (Banco Unión, Cremi) devoraron esa bolsa; por eso -luego de una de las negociaciones más importantes entre el Estado y los banqueros- el gobierno tuvo que asistir y avalar las deudas que iba adquiriendo el Fondo.

Así, el Fobaproa resultó un portero indemne porque nunca tuvo línea defensiva y porque los tiros (los malos préstamos que por ley tuvo que asumir) se multiplicaron. No había manera de vigilar a los bancos y sin embargo existía un compromiso legal para apoyarlos. Por la falta de instrumentos de supervisión, el Estado no sabía bien qué era lo que estaba respaldando.

\section{FOBAPROA EN ACCIÓN: ¿ERA LA ÚNICA AL- TERNATIVA?}

Pero llegó la crisis monetaria de 1994 y las contingencias, las deudas incobrables, las tasas de interés, todo junto, se multiplicaron. Decenas de miles de mexicanos quedaron involucrados en el desastre. Y solo se contaba con un instrumento de salvación: el Fobaproa. 
Todas las deudas crecieron porque las tasas subieron; al mismo tiempo creció la imposibilidad de pagarlas: descendió el empleo, el salario, y se destruyeron las expectativas de inversión y la crisis la cartera vencida se duplicó: de 7.1 pasó a representar el 16 por ciento de la cartera total.

La ley, $\tan$ favorable a los bancos para realizar cualquier tipo de operaciones, les da la espalda al final ya que es muy difícil hacer pagar a sus deudores. La ley de quiebras por ejemplo, defiende a quien se declara insolvente, y por sólo ese hecho deja de pagar intereses. Dependiendo del juez, el asunto puede ser declarado mercantil o civil, con rutas de solución totalmente diferentes e imprevisibles. Lo más importante es quizás, la franca ignorancia de los jueces al enfrentar problemas de carácter financiero. Es decir, si la autoridad y la ley permitieron a los banqueros sumirse en una francachela crediticia durante años, de repente se quedan sin instrumentos para poder cobrar.

Así, en enero de 1995 las autoridades se encontraron frente a un escenario económico que se degradaba rápidamente. El gobierno eligió una de las opciones disponibles: compró la cartera vencida. Los bancos la ofrecieron atropelladamente; al principio formaron contratos para compartir el riesgo, después no hubo tiempo ni cuidado ni siquiera para eso. Ante la contingencia y la crítica situación, no medió un criterio uniforme y constante, primó el azar y la arbitrariedad.

Las autoridades han dicho que no había otras alternativas disponibles, pero la experiencia internacional permitía divisar al menos dos: 1) capitalizar (prestar dinero) a los bancos y subsidiar a los deudores (ofreciendo recursos públicos para programas de reducción y estímulo de pagos, es este el esquema japonés) ${ }^{2}$, y 2) que el Estado se hiciera cargo de los bancos más frágiles para administrarlos temporalmente y capitalizarlos, de este modo no tendría carteras vencidas (que cada vez valen menos) sino acciones bancarias cuyo valor aumentaría conforme la situación volvía a la normalidad ${ }^{3}$. Incluso pudo pensarse en programas de cierres o de fusiones de aquellos bancos que son definitivamente inviables. Según Alan Greenspan si se hace con orden, si se rescata a los ahorradores, no hay porque espantarse de la quiebra de uno o dos bancos, "el número ideal de quiebras bancarias nunca puede ser igual a cero, siempre hay accidentes, malas administraciones que cancelan el desarrollo de esas instituciones; hay que reconocerlo si no se quiere seguir dando respiración a un muerto".

Los bancos pudieron seguir funcionando es cierto, y la gente conservó la confianza de que podía llegar a su banco y retirar sus ahorros normalmente. Pero las instituciones bancarias permanecieron en un estado extremadamente vulnerable, con poco capital, con muchas deudas dependientes del auxilio prestado por el Fobaproa.

Un respaldo como el elegido por el gobierno no podía sino crecer espectacularmente, y no sólo por la crisis. Cuando los bancos trasladaban las deudas al Fondo al mismo tiempo se desentendían de su administración. Una vez que la deuda entraba en el barril del Fobaproa los banqueros perdían incentivos para renegociarla o cobrarla. Así, un montón de pasivos entraron a una hibernación que sin embargo seguía generando intereses. Según Luis Rubio este meca- nismo explica, más que cualquier otra cosa el crecimiento exponencial de la deuda acumulada en el fondo: nadie se ocupó de cobrar.

El propio Rubio anota un punto esencial: el problema del Fobaproa se explica por ese encadenamiento de errores, mucho más que a la deshonestidad o el robo. De los 65 mil millones de dólares que contiene el Fobaproa, los tres fraudes de banqueros hasta ahora detectados (Carlos Cabal, Angel Rodríguez y Jorge Lankenau) suman 4 mil 200 millones de dólares "cifra enorme en sí misma pero que representa el 6 por ciento del total".

En resumidas cuentas: si bien es cierto que la crisis bancaria no surgió en este sexenio, también lo es que había otras alternativas, otras formas para encararla. Y peor, una vez elegida la alternativa de compra de cartera vencida, fue mal ejecutada, mal administrada, de ahí su enorme crecimiento.

En gran parte por eso no existen cifras exactas sobre el Fobaproa: se compró cartera con información insuficiente y luego nadie se ocupó de cobrarla. En su informe anual de 1995 el Banco de México proyectó que el costo del rescate sería únicamente de 5.5 por ciento del producto. Para 1996, la cifra ya era calculada en 8.4 por ciento. Sin embargo, hace unos meses, cuando el Presidente Zedillo decide proponer la conversión a deuda pública, la estimación ya alcanzaba el 16 por ciento del producto, casi el triple del cálculo hecho inicialmente. La alternativa elegida no parece arrojar buenos resultados políticos, tampoco financieros.

\section{LOS PARTIDOS A ESCENA}

La propuesta original del gobierno había girado alrededor de seis ejes: fortalecer la regulación y supervisión a los bancos; limitar la protección de los depósitos es decir; que los grandes ahorradores se hagan responsables de la condición de los bancos a los que llevan su dinero; recuperar al máximo los activos de Fobaproa; abrir a la banca a capitales de accionistas extranjeros; darle mas atribuciones al Banco de México para regular el régimen de cambio, y la que ha resultado más polémica, transformar en deuda directa los pasivos de Fobaproa.

El PRD se encargó de poner el tema en el centro de la discusión. Cuando reclama una atención pública y una rectificación a la propuesta del ejecutivo, está en lo correcto. En respuesta a aquella iniciativa presentó "Fobaproa: el gran atentado contra la economía popular". En once apartados disecciona el problema: arguye ilegalidad e inconstitucionalidad en varias de las acciones del gobierno, ineficiencia administrativa, impunidad, insuficiente apoyo a pequeños y medianos deudores, subraya el alto margen financiero con el que operaron los bancos entre 91 y 94 . Son 17 páginas de diagnóstico y denuncia, y sólo dos y media de solución, que no alcanza a concretar una salida, sobre todo en el aspecto esencial: la convertibilidad de los pasivos a deuda pública (lo abordaremos en el último apartado).

\footnotetext{
2. Esta es la opción expuesta por Luis Rubio.
}

3. Esta es la opción manejada por Ricardo Solís. 
Pero el defecto mayor radica en la extrema polarización del planteamiento: incluso ahí y donde existen coincidencias con el gobierno, el PRD retrocede, lo que crea la apariencia de un callejón sin salida.

Ese fue el trabajo del PAN: pensar una propuesta que recoja prácticamente todas las objeciones del PRD, pero formuladas y proyectadas hacia propuestas que conectan con el PRI y el gobierno. La propuesta del PAN obligó a un movimiento importante del PRI, y en el informe presidencial, también propició modificaciones en la postura del gobierno.

Creo que es posible señalar las contribuciones que los partidos de oposición han hecho al debate: cuestionar acerca de la gestación de la deuda contingente, señalar los errores, corrupción e ineficiencia implicados. La propuesta original del gobierno omitió por completo reformar las leyes actuales para castigar los fraudes de "cuello blanco". Tampoco presentó una nueva ley de quiebra ni reformas para sancionar debidamente el incumplimiento en los pagos, pero sobre todo, el gobierno sostenía que ya se había hecho todo lo posible para distribuir los costos de la crisis bancaria, que ya había apoyado en todo lo posible a los deudores y que ya había aplicado el peso de la ley contra todos los defraudadores. La oposición y sectores de la opinión pública, han demostrado que no es así. Y ese es un motivo para celebrar la deliberación abierta.

Las posturas de los partidos (incluyendo al PRI) son un rechazo generalizado a los supuestos del gobierno: no ha sido suficiente el apoyo a los deudores, la banca tiene que asumir más costos por sus pecados crediticios, hay que mejorar el trabajo para distribuir los costos y asegurar la persecución a los defraudadores, propiciar condiciones para asegurar el pago de deudas y evitar el ambiente de impunidad. Esta es la ganancia neta de nuestra discusión.

Sin embargo, los partidos fallan en varios aspectos importantes; por ejemplo, no hay por ningún lado una propuesta de capitalización a la banca; lo que es más algunas de las iniciativas más importantes no soportan la prueba de la factibilidad. Por ejemplo, ¿de dónde va a salir el dinero y cuáles son las características de los nuevos programas de apoyo a deudores?, ¿cómo va a funcionar la nueva institución de seguros de los depósitos?. Pongamos un ejemplo de viabilidad aún con la alternativa partidista más moderada: dice el PRI que se debe obligar a los bancos a absorber el 30 por ciento de los pasivos de Fobaproa (unos 185 mil millones de pesos). Pero resulta que el capital contable total de la banca nacional es apenas de unos 85 mil millones, o sea, la propuesta moderada alcanza para quebrar a la banca de manera inmediata.

Por lo que la pregunta es: ¿Cómo reducir los pasivos de Fobaproa sin convertirlos en deuda pública? Este es el núcleo final e ineludible de la discusión.

\section{LA CONVERSIÓN A DEUDA PÚBLICA: EL NÚ- CLEO DE LA DISCORDIA}

Es aquí donde las posiciones se han vuelto irreductibles. Fue esta la pregunta estelar de la consulta perredista y es el núcleo que no aborda explícitamente la propuesta del PAN.

¿Por qué debe aprobarse ese punto de la propuesta del gobierno? ¿por qué debe haber esa conversión? Como sabe- mos el Fobaproa está constituido por cartera vencida de los bancos. El gobierno los respaldó mediante unos "supercetes", un invento de los ingenieros financieros que tiene una característica especial: no pagan intereses mensuales o trimestrales sino que se acumulan hasta su vencimiento en diez años. O sea: los bancos no están recibiendo nada de dinero por su convenio en Fobaproa; el problema es que para muchas instituciones esto puede significar dejar de ser viables, pues no cuentan con liquidez suficiente para enfrentar sus obligaciones cotidianas. En la contabilidad, en los libros, los bancos están respaldados y sus depósitos y depositantes también. Pero, como advierte Ricardo Solís, pueden no tener muy pronto la solvencia para operar.

La transformación que solicita el Presidente tiene ese efecto: transformar los "supercetes" en cetes normales, que pagan intereses, mensual o trimestralmente. Esto haría que los bancos recibieran dinero líquido rápidamente, de manera constante y segura.

Uno puede estar en contra de la decisión Fobaproa, pero sería un error todavía más grave, suspender la operación con el paciente abierto a la mitad de la cirugía. Hay un problema de liquidez grave que la conversión soluciona.

Pero hay más razones que la apoyan: ya se han pagado 80 mil 500 pesos diluidos en los últimos tres años, pero el grueso de la deuda sigue siendo papel. La transformación a cetes facilita su compra, su venta, da flexibilidad para posponer o acelerar su pago si nuevas condiciones lo permiten. En otras palabras, la conversión facilita la administración de la deuda, por lo tanto facilita su reducción.

Luego, la tasa de un cete normal es más baja que la de las garantías puestas en el Fobaproa, es decir, reconocer esa deuda como pasivo del gobierno, baja los intereses de la deuda misma, y por lo tanto representa automáticamente un menor costo para el gobierno, y para nosotros, los contribuyentes.

Y finalmente, hay otro ángulo igualmente importante: si no se da esa conversión, el servicio de la deuda tendría que ser autorizado específicamente, cada presupuesto, año tras año, hasta el décimo. Si fuera deuda pública, en cambio, ya no tendrían que ser autorizados en lo particular-como ocurrió en 1997- y por lo tanto no estarían sujetos a los vaivenes de la lucha política. Eso despejaría importantes incógnitas sobre el sistema financiero mexicano, automáticamente, se le daría fortaleza y certidumbre. Y si esto no lo logramos, cualquier otro avance -en términos de transparencia, justicia, castigo a los culpables- será irrelevante. Los bancos fuertes son las únicas instituciones de las que la economía capitalista no puede prescindir (Schumpeter dixit).

\section{HACIA UNA CONCLUSIÓN}

Hay un desenlace pesimista: el debate sobre el Fobaproa no tiene lugar en el vacío, se verifica en un momento extraordinariamente turbulento, The Economist afirma incluso que éste es el periodo de mayor inestabilidad financiera mundial desde la conclusión de segunda guerra mundial. Y México es parte de los eslabones débiles de las finanzas internacionales, un punto propenso a los ataques especula- 
tivos, al nerviosismo, a las estampidas del capital golondrino. En esas condiciones la ausencia de acuerdo en torno a las bases operativas y legales del sistema bancario puede significar en México el desencadenamiento de una crisis financiera que va a perjudicar a todos, especialmente, a los más pobres. No se trata de poner espantasuegras en el debate, sino de reconocer que el acuerdo se ha vuelto una necesidad de la nación, una condición de la viabilidad económica del país, más allá de los partidos mismos y por supuesto más allá del año 2000.

Pero aún cabe un desenlace optimista; si las fuerzas políticas hacen bien su trabajo, el asunto del Fobaproa podría convertirse en un hito: la democracia, el pluralismo, la ausencia de mayorías absolutas, a pesar de sus dificultades, roces, discusiones agrias, produce gobierno, y lo que es más, produce mejor gobierno.

Habríamos entendido que el problema no lo creó el Fobaproa sino una serie concomitante de errores y decisiones políticas: condiciones de la privatización permisivas y vulnerables; pagos cruzados y "autopréstamos" para comprar a esas instituciones; pésimos administradores hechos banqueros; falta de supervisión a la banca; normas oligopólicas; leyes mercantiles y penales sumamente tolerantes con los delincuentes financieros; una ley de quiebras ambigua y que hace muy complicado que los bancos cobren o ejecuten las garantías; un seguro de depósito que se quedó atrasado por años y que ha pasado el costo a los contribuyentes sin haberlo diferenciado en función del tamaño de los depósitos.

Si a su vez pudiéramos entender que existen salidas viables, que las coincidencias son suficientes, que la propuesta del gobierno debe ser corregida y sustancialmente ampliada y que existen fórmulas en las que la Conversión a deuda pública no implica obstáculo alguno para hacer pagar a quien tenga responsabilidad, que las auditorías prosigan y que las operaciones ilícitas sean castigadas (y descontadas de la deuda total).

Y finalmente, si los diputados dieran un salto adicional, hacia la discusión de la banca y de sus funciones para el desarrollo, si pudiéramos elaborar una estrategia para financiar el crecimiento de nuestro país, a partir de una banca revitalizada, estrictamente vigilada, estaríamos abriendo una puerta franca a la viabilidad económica de México.

Todo depende del talento político y de que los partidos sepan diferenciar su interés del interés general. El fideicomiso habría sido la ocasión de una acción política y pedagógica de grandes proporciones: un asunto público que se informa, se debate a todos los niveles, se ventila en todos los escenarios posibles, la ciudadanía se involucra y presta atención; el gobierno es capaz de corregir, los partidos son capaces de elaborar propuestas rigurosas y de plantearlas abiertamente, con seriedad; se pueden poner de acuerdo, y en su laboratorio natural -el Congreso de la Unión-generan una ley y un conjunto de medidas que no sólo corrigen y mejoran sustancialmente la propuesta del ejecutivo sino que sientan las bases -a largo plazo- para la reforma de uno de los eslabones históricos más débiles de la economía mexicana, el sistema bancario.

\section{BIBLIOGRAFÍA}

Esta recapitulación se benefició de varios autores que han expuesto públicamente sus posturas, como Enrique Quintana o Jonathan Heath. Y se fundó en una bibliografía mínima:

Rubio, Luis (1998): Fobaproa o las consecuencias de la ineptitud. México, Nexos, julio.

Solís Rosales, Ricardo (1998): La crisis bancaria en México (1994-97). UAM.

HAUSMANN, Ricardo y Liliana ROJAS SuÁREZ (1997): Las crisis bancarias en América Latina. BID-FCE.

Estudios Económicos de la OCDE-1998. México, 1998.

Secretaría de Hacienda (1998): Fobaproa: la verdadera historia. 


\section{RESUMEN}

Este artículo analiza la crisis bancaria que enfrenta México y que tiene su origen en 1991, fecha a partir de la cual se inicia la privatización de la banca. Dentro de las razones que generaron esta crisis se encuentran, entre otras: que el valor de compra fue superior al valor real de los bancos, hubo una excesiva confianza de banqueros y gobierno en el crecimiento económico, no se implementaron mecanismos de vigilancia y control adecuados y se implementaron inadecuadas estrategias de crédito.

Esta crisis quizo ser superada a través del Fondo Bancario de Protección y Rescate al Ahorro (Fobaproa), institución creada con el fin de "realizar operaciones preventivas tendientes a evitar problemas financieros...". Esta institución es una bolsa de recursos aportados por los propios banqueros, que en la primera etapa de la crisis fue consumida, por lo que el gobierno tuvo que respaldar las deudas adquiridas por éste.

$\mathrm{La}$ ausencia de un acuerdo en torno a las bases operativas y legales del sistema bancario puede llevar a un caos financiero que afecte a la sociedad mexicana, especialmente a la clase baja.

Palabras clave: Banca mexicana, inversión nacional, Fobaproa, crisis financiera, crisis bancaria.

\section{ABSTRACT}

This article analyses the bank crisis that Mexico is confronting whose origins are situated in 1991, when the process of privatization of the banks started. Among others, the reasons that generated this crisis are the following: the purchase value was greater than the real value of the banks, there was an excessive confidence of the bankers and the government on the economic growth, adequate vigilance and control mechanisms were never implemented and inadequate credit strategies were executed.

The attempt to overcome the crisis was done through the Fondo Bancario de Protección y Rescate al Aborro (Fobaproa), an institution created with the aim to "carry out preventive operations tending to avoid financial problems...". This institution is a stock of resources provided by the bankers themselves, that was depleted in the first stage of the crisis, and hence the government had to back the acquired debt.

The absence of an agreement around the operational and legal basis of the banking system can lead to a financial chaos affecting Mexican society, especially the working class.

Key words: Mexican banking, national investment, Fobaproa, financial crisis, banking crisis.

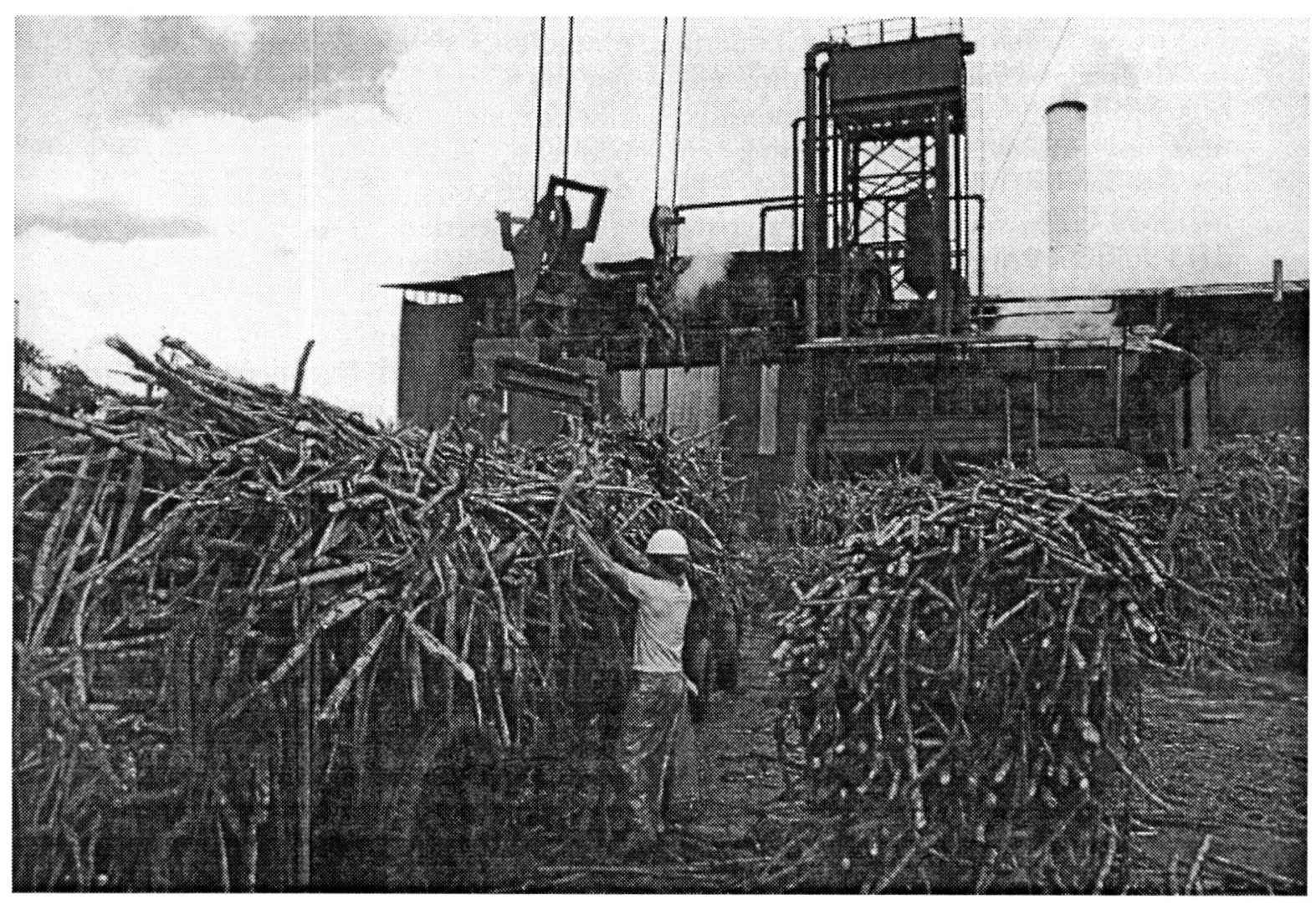

